\title{
Azathioprine in rheumatoid arthritis: double-blind study of full versus half doses versus placebo
}

\author{
J. WOODLAND, D. M. CHAPUT DE SAINTONGE, S. J. W. EVANS, \\ V. L. SHARMAN, AND H. L. F. CURREY
}

From the London Hospital, London E1 1 BB

SUMMARY To test whether azathioprine is effective in rheumatoid arthritis in doses smaller than those normally used the drug was tested at 2 dosage levels, 2.5 and $1.25 \mathrm{mg} / \mathrm{kg} / \mathrm{day}(2.5 \mathrm{AZ}$ and $1 \cdot 25 \mathrm{AZ}$ ), against placebo under double-blind conditions over 24 weeks. Dropouts were 7 out of 15 in the $2.5 \mathrm{AZ}$ group, 4 out of 14 in the $1.25 \mathrm{AZ}$ group, and 2 out of 13 in the placebo group. Some significant improvement occurred in all 3 groups, including those on placebo. However, the $2 \cdot 5 \mathrm{AZ}$ group fared significantly better than the placebo group, while the $1 \cdot 25 \mathrm{AZ}$ group results tended to fall between the other 2 groups. We conclude that, in order to obtain the reported effectiveness of azathioprine in rheumatoid arthritis, it is necessary to start treatment with $2.5 \mathrm{mg} / \mathrm{kg} / \mathrm{day}$. Halving this dosage reduces the effectiveness of the drug.

Active and progressive rheumatoid arthritis is usually treated with one of the 'slow acting' group of drugs which includes gold, penicillamine, and the 'immunosuppressive' (antiproliferative) agents. Potentially serious toxicity combined with the need for regular blood count monitoring limits the usefulness of these 'slow acting' drugs. Azathioprine is perhaps the easiest of this group to manage. ${ }^{1}$ However, the slight but probable oncogenic hazard remains a major drawback to its usefulness. ${ }^{2} 3$ How antiproliferative drugs predispose to neoplasia is unknown. The risk has not been shown to be clearly related to dose, ${ }^{3}$ but it nevertheless seems sensible to limit the dosage level to that which will achieve a satisfactory therapeutic effect. Early studies in rheumatoid arthritis ${ }^{4}$ used a dose of $2.5 \mathrm{mg} / \mathrm{kg} / \mathrm{day}$, based on the successful use of this drug in renal transplantation. Subsequent attempts to test the effectiveness of low doses have not given clear results. ${ }^{5-8}$ We have therefore tested the drug at 2 doses-2.5 and $1.25 \mathrm{mg} / \mathrm{kg} /$ day-against placebo under double-blind conditions.

\section{Patients and methods}

Patients admitted to the trial were required to have definite rheumatoid arthritis shown to be seropositive (latex test $>1: 80$ ) and erosive within the Accepted for publication 4 September 1980.

Correspondence to Professor H. L. F. Currey, Bone and Joint Research Unit, Arthritis and Rheumatism Council Building, 25-29 Ashfield Street, London E1 2AD. the past 3 months. Their disease had to be severe enough to warrant treatment with azathioprine, either because of active and persistent inflammatory joint disease despite full anti-inflammatory and analgesic therapy or because of progression of radiological damage. A blood count obtained within 1 month of entry had to satisfy the following minimum criteria: total leucocytes $4.0 \times 10^{9} / 1$, platelets $175 \times 10^{9} / 1$, and haemoglobin of $10 \mathrm{~g} / \mathrm{dl}$. Patients previously treated with azathioprine, or who within the previous 3 months had received gold, corticosteroids, penicillamine, or immunosuppressive drugs, were excluded. Other reasons for exclusion were age under 20 , the possibility of pregnancy, persistent troublesome dyspepsia, and evidence of liver or renal disease (blood urea over $7 \mathrm{mmol} / \mathrm{l}$ ).

There were 3 treatment groups: azathioprine $2.5 \mathrm{mg} / \mathrm{kg}$ daily $(2.5 \mathrm{AZ}$ ), azathioprine $1.25 \mathrm{mg} / \mathrm{kg}$ daily $(1 \cdot 25 \mathrm{AZ})$, and placebo. The drugs were prepared as matching tablets and given in 2 divided doses daily. Patients were stratified for duration of disease (less than or more than 5 years) and for the severity of arthritis (joint number less than 6, 6 to 9, or more than 9). Allocation to a treatment group was balanced by the process of 'minimisation'.'

On entry to the trial patients were invariably on full dosages of anti-inflammatory drugs, and these were continued throughout the trial, which was carried out under double-blind conditions. A trial controller allocated treatment once the initial assessments (week -2 ) had been carried out. 
The following clinical assessments were made at the beginning of the trial and at monthly intervals: functional capacity (Steinbrocker); duration of morning stiffness; patient's assessment of severity of joint symptoms over the preceding 7 days, both on a 4-point scale (nil to severe), and a visual analogue scale. For both of these measurements higher scores indicate worse symptoms. Joint score was the number of limb joints painful on full active movement. With the hands and feet each counting as 1 unit until the maximum score was 16 . Grip strength was measured with a $200 \mathrm{~mm}$ circumference inflatable bag. Drug toxicity was sought with the following question: 'Has the treatment upset you in any way since your last visit?'. In addition direct questions were asked about sore throat, mouth ulcers, and purpura. All unused trial tablets were returned and counted, and a record was kept of analgesic consumption. Blood counts were performed at weeks $-2,0,+2,+4$, then 4-weekly. Latex, SCAT, and SGOT tests were carried out 3-monthly.

\section{STATISTICAL ANALYSIS}

Analysis of the effects of treatment was carried out by comparing the mean values of the initial observations ( -2 and 0 weeks) with those at monthly intervals thereafter. Multiple regression analysis identified important determinants of the treatment effect, and these were later used in an analysis of covariance comparing changes between the treatments. This analysis corrected for the contribution to the treatment effect made by variables other than the treatment itself, particularly the values at entry. The value of changes in morning stiffness was transformed $\left(\log _{e}\right)$ for the calculations because of its skewed distribution. The effect of compliance was studied by using the number of tablets not returned as a covariate, thereby measuring the effect of treatments independently of the effects of noncompliance. ${ }^{10} \mathrm{~A}$ few patients took so little of their allocated treatment that they effectively joined another group. The trial was further reanalysed after these patients had been reallocated to the appropriate treatment groups. A discriminant analysis was performed on all variables on admission to discover whether there were any early indications of treatment success or of dropout. The measure of treatment success was the physician's overall judgment of the changes in all trial variables.

\section{Results}

Forty-two patients entered the trial. Fifteen were allocated to $2.5 \mathrm{AZ}, 14$ to $1.25 \mathrm{AZ}$, and 13 to placebo. Patients allocated to each of these groups did not differ significantly with regard to duration of

Table 1 Initial values and changes at 24 weeks

\begin{tabular}{|c|c|c|c|c|c|}
\hline Variable & Treatments & Initial value $(S D)$ & Change at 24 weeks $(95 \% C L)$ & $\begin{array}{l}\text { Significance of } \\
\text { change }(p<)\end{array}$ & $\begin{array}{l}\text { Significance of } \\
\text { difference }(p<)\end{array}$ \\
\hline $\begin{array}{l}\text { Functional capacity } \\
\text { (grade) }\end{array}$ & $\begin{array}{l}\text { Placebo } \\
1 \cdot 25 \mathrm{AZ} \\
2 \cdot 5 \mathrm{AZ}\end{array}$ & $\begin{array}{l}1 \cdot 73(0 \cdot 75) \\
1 \cdot 64(0 \cdot 86) \\
1 \cdot 13(0 \cdot 52)\end{array}$ & $\begin{array}{l}-0.10(0.26,-0.46) \\
-0.31(0.07,-0.69) \\
-0.34(0.08,-0.76)\end{array}$ & $\begin{array}{l}\text { NS } \\
\text { NS } \\
\text { NS }\end{array}$ & NS \\
\hline $\begin{array}{l}\text { Morning stiffness } \\
\text { (min) }\end{array}$ & $\begin{array}{l}\text { Placebo } \\
1 \cdot 25 \mathrm{AZ} \\
2 \cdot 5 \mathrm{AZ}\end{array}$ & $\begin{array}{l}57 \cdot 5(25,73)^{*} \\
65 \cdot 0(22,82)^{*} \\
45 \cdot 0(7,66)^{*}\end{array}$ & $\begin{array}{l}-1 \cdot 2(-29,19)^{*} \\
-45(-78,-31)^{*} \\
-27(-60,-8)^{*}\end{array}$ & $\begin{array}{l}\text { NS } \\
0.05 \\
0.05\end{array}$ & 0.05 \\
\hline $\begin{array}{l}\text { Patient assessment } \\
\text { (analogue score) }\end{array}$ & $\begin{array}{l}\text { Placebo } \\
1 \cdot 25 \mathrm{AZ} \\
2 \cdot 5 \mathrm{AZ}\end{array}$ & $\begin{array}{l}51 \cdot 4(16 \cdot 4) \\
56 \cdot 9(11 \cdot 4) \\
44 \cdot 8(19 \cdot 1)\end{array}$ & $\begin{array}{l}-13 \cdot 65(-2 \cdot 60,-24 \cdot 69) \\
-25 \cdot 39(-13 \cdot 81,-36 \cdot 97) \\
-38 \cdot 74(-25 \cdot 79,-51 \cdot 69)\end{array}$ & $\begin{array}{l}0.05 \\
0 \cdot 01 \\
0 \cdot 001\end{array}$ & 0.05 \\
\hline $\begin{array}{l}\text { Patient assessment } \\
\text { (grade, } 4 \text { point scale) }\end{array}$ & $\begin{array}{l}\text { Placebo } \\
1 \cdot 25 \mathrm{AZ} \\
2 \cdot 5 \mathrm{AZ}\end{array}$ & $\begin{array}{l}3 \cdot 15(1 \cdot 07) \\
3 \cdot 36(0 \cdot 93) \\
2 \cdot 73(1 \cdot 10)\end{array}$ & $\begin{array}{l}-0.72(-0 \cdot 19,-1 \cdot 23) \\
-0.77(-0 \cdot 26,-1 \cdot 28) \\
-2 \cdot 18(-1 \cdot 56,-2 \cdot 80)\end{array}$ & $\begin{array}{l}0.05 \\
0.05 \\
0.001\end{array}$ & 0.01 \\
\hline Joint score & $\begin{array}{l}\text { Placebo } \\
1 \cdot 25 \mathrm{AZ} \\
2 \cdot 5 \mathrm{AZ}\end{array}$ & $\begin{array}{l}6 \cdot 85(1 \cdot 85) \\
7 \cdot 25(2 \cdot 84) \\
7 \cdot 23(2 \cdot 68)\end{array}$ & $\begin{array}{l}-2 \cdot 03(-0 \cdot 29,-3 \cdot 77) \\
-2 \cdot 81(0 \cdot 98,-4 \cdot 64) \\
-4 \cdot 32(-2 \cdot 79,-6 \cdot 36)\end{array}$ & $\begin{array}{l}0.05 \\
0.02 \\
0.01\end{array}$ & \} NS \\
\hline $\begin{array}{l}\text { Grip strength } \\
(\mathrm{mmHg})\end{array}$ & $\begin{array}{l}\text { Placebo } \\
1 \cdot 25 \mathrm{AZ} \\
2 \cdot 5 \mathrm{AZ}\end{array}$ & $\begin{array}{l}119(63 \cdot 1) \\
124(57 \cdot 7) \\
116(39 \cdot 6)\end{array}$ & $\begin{array}{c}-2 \cdot 2(11 \cdot 56,-15 \cdot 92) \\
12 \cdot 9(27 \cdot 36,-1 \cdot 47) \\
31 \cdot 6(47 \cdot 69,15 \cdot 45)\end{array}$ & $\begin{array}{l}\text { NS } \\
\mathrm{NS} \\
0 \cdot \mathrm{C} 1\end{array}$ & 0.01 \\
\hline Haemoglobin & $\begin{array}{l}\text { Placebo } \\
1 \cdot 25 \mathrm{AZ} \\
2 \cdot 5 \mathrm{AZ}\end{array}$ & $\begin{array}{l}11 \cdot 6(1 \cdot 55) \\
12 \cdot 1(1 \cdot 35) \\
12 \cdot 7(1 \cdot 63)\end{array}$ & $\begin{array}{r}0.24(0.81,-0.33) \\
-0.45(0.22,-1.12) \\
-0.15(0.52,-0.82)\end{array}$ & $\begin{array}{l}\text { NS } \\
\text { NS } \\
\text { NS }\end{array}$ & \}$N S$ \\
\hline $\operatorname{ESR}(\mathrm{mm} / \mathrm{h})$ & $\begin{array}{l}\text { Placebo } \\
1 \cdot 25 \mathrm{AZ} \\
2 \cdot 5 \mathrm{AZ}\end{array}$ & $\begin{array}{l}60 \cdot 0(21 \cdot 6) \\
62 \cdot 3(30 \cdot 7) \\
49 \cdot 5(24 \cdot 6)\end{array}$ & $\begin{array}{r}-4 \cdot 7(6 \cdot 78,-16 \cdot 18) \\
-11 \cdot 8(1 \cdot 68,-25 \cdot 24) \\
-8 \cdot 1(5 \cdot 38,-21 \cdot 54)\end{array}$ & $\begin{array}{l}\text { NS } \\
\text { NS } \\
\text { NS }\end{array}$ & \}$N S$ \\
\hline
\end{tabular}

* Median and midquartile range. $\mathrm{CL}=$ confidence limits. $\mathrm{NS}=$ not significant. 
disease, age, and sex distribution, nor was there any significant difference between the groups with respect to the initial clinical or laboratory assessments except functional capacity, which was significantly better in the $2.5 \mathrm{AZ}$ group than in the placebo group.

Table 1 shows the starting values for all the variables studied and the overall changes without taking compliance into account. Fig. 1 illustrates the monthly changes in those variables showing significant treatment effects.

Joint score. Changes here were found to be significantly dependent on the initial values. All treatment groups (including placebo) improved significantly during the trial, but the $2.5 \mathrm{AZ}$ group had improved more than placebo at 8 and 20 weeks and was also better than $1.25 \mathrm{AZ}$ at 20 weeks. Early superiority of $1.25 \mathrm{AZ}$ over placebo at 4 and 8 weeks was not apparent later in the trial.

Patient assessment (visual analogue). All treatment groups improved significantly during the trial but $2.5 \mathrm{AZ}$ significantly more so than placebo at 12 and 24 weeks.

Patient assessment (4-point scale). All treatment groups improved significantly during the trial, and by the end $2.5 \mathrm{AZ}$ was considerably better than $1 \cdot 25 \mathrm{AZ}$ and placebo.

Morning stiffness. Both $2 \cdot 5 \mathrm{AZ}$ and $1 \cdot 25 \mathrm{AZ}$ improved significantly during the trial and were better than placebo by 24 weeks.

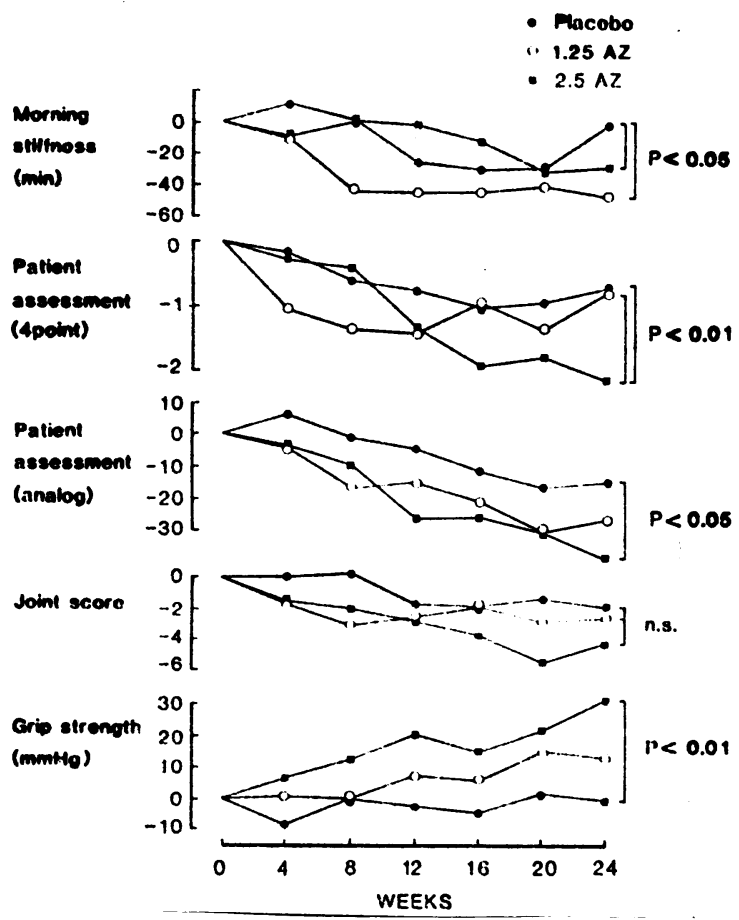

Fig. 1 Sequential changes from the initial values for 5 variables. Placebo: $0,1 \cdot 25 \mathrm{AZ}: 0,2 \cdot 5 \mathrm{AZ}$ :

Grip strength. $2 \cdot 5 \mathrm{AZ}$ was significantly better than placebo at 24 weeks.

Fig. 1 illustrates the pattern of change in these variables over the 6 months. In general all improved

Table 2 Patients withdrawn from the trial

\begin{tabular}{|c|c|c|c|c|}
\hline Treatment group & $\operatorname{Sex}$ & $\begin{array}{l}\text { Time of withdrawal } \\
\text { in weeks }\end{array}$ & Reason for withdrawal & Other drugs \\
\hline $2 \cdot 5 \mathrm{AZ}$ & $\mathbf{M}$ & 1 & Vomiting, rash & $\begin{array}{l}\text { Ibuprofen } \\
\text { Distalgesic* } \\
\text { Indomethacin }\end{array}$ \\
\hline $2 \cdot 5 \mathrm{AZ}$ & $\mathbf{F}$ & 2 & Generally unwell & $\begin{array}{l}\text { Ketoprofen } \\
\text { Indomethacin }\end{array}$ \\
\hline $2 \cdot 5 \mathrm{AZ}$ & $\mathbf{F}$ & 3 & Nausea, headache, itching, sore tongue & $\begin{array}{l}\text { Paracetomol } \\
\text { Fenoprofen }\end{array}$ \\
\hline $2 \cdot 5 \mathrm{AZ}$ & $\mathbf{M}$ & 3 & Rash, leucopenia & Aspirin \\
\hline $2 \cdot 5 \mathrm{AZ}$ & $\mathbf{M}$ & 8 & Anaemia? bleeding & $\begin{array}{l}\text { Aspirin } \\
\text { Indomethacin }\end{array}$ \\
\hline $\begin{array}{l}2 \cdot 5 \mathrm{AZ} \\
2 \cdot 5 \mathrm{AZ}\end{array}$ & $\begin{array}{l}\mathbf{M} \\
\mathbf{M}\end{array}$ & $\begin{array}{l}11 \\
12\end{array}$ & $\begin{array}{l}\text { Vomiting } \\
\text { Headache, vomiting }\end{array}$ & $\begin{array}{l}\text { Indomethacin } \\
\text { Aspirin } \\
\text { Indomethacin }\end{array}$ \\
\hline $1 \cdot 25 \mathrm{AZ}$ & $\mathbf{F}$ & 3 & Vomiting, giddiness & $\begin{array}{l}\text { Aspirin } \\
\text { Indomethacin }\end{array}$ \\
\hline $\begin{array}{l}1.25 \mathrm{AZ} \\
1.25 \mathrm{AZ} \\
1.25 \mathrm{AZ}\end{array}$ & $\begin{array}{l}\mathbf{M} \\
\mathbf{M} \\
\mathbf{M}\end{array}$ & $\begin{array}{r}4 \\
6 \\
15\end{array}$ & $\begin{array}{l}\text { Left ventricular failure } \\
\text { Weakness } \\
\text { Treatment failure }\end{array}$ & $\begin{array}{l}\text { Indomethacin } \\
\text { Ketoprofen } \\
\text { Naproxen } \\
\text { Indomethacin }\end{array}$ \\
\hline Placebo & $\mathbf{F}$ & 4 & Rash & $\begin{array}{l}\text { Naproxen } \\
\text { Distalgesic }\end{array}$ \\
\hline Placebo & $\mathbf{M}$ & 6 & Headache & Ibuprofen \\
\hline
\end{tabular}

*Dextropropoxyphene HIl and paracetamol. 
gradually over the period of the study, and, except for grip strength, the placebo group improved significantly too. However, there was throughout a clear trend for the high dose to be more effective than the half dose, which in turn was more effective than placebo.

Functional capacity, haemoglobin, and erythrocyte sedimentation rate showed no treatment effect, although, as with the clinical parameters, changes were dependent on the initial values.

Withdrawals. There were 7 withdrawals (47\%) from $2 \cdot 5 \mathrm{AZ}, 4(29 \%)$ from $1 \cdot 25 \mathrm{AZ}$, and $2(15 \%)$ from placebo. This difference in number of patients withdrawn did not reach statistical significance. Nine out of 14 men were withdrawn compared with 4 out of 28 women, but there was a tendency for there to be more males in the high-dose group. None of these differences reached significance. The reasons for withdrawal are shown in Table 2 . Generally withdrawals tended to occur early in the trial, and only 1 patient $(1 \cdot 25 \mathrm{AZ}$ group) was withdrawn because of lack of effectiveness. Discriminant analysis showed that of the entry variables male sex and mild symptoms (on the visual analogue scale) correlated best with dropout.

Compliance. The effect of noncompliance did not significantly alter the results.

Analgesic consumption. There were no consistent differences between the groups. In particular the improvement in the $2.5 \mathrm{AZ}$ group could not be accounted for by greater analgesic consumption.

\section{PHYSICIANS' ASSESSMENT}

At the end of the trial the physicians were presented with a set of figures giving initial and final values for each variable for all patients. The physicians were then asked to grade ('blind') the response of each patient. Patients judged to have improved significantly contained more $2.5 \mathrm{AZ}$ patients than either of the other treatments. Discriminant analysis suggested that patients who did well had a high initial joint score, received $2.5 \mathrm{AZ}$, and at 4 weeks had little morning stiffness and good functional capacity. However, early improvements in morning stiffness and functional capacity were not such good predictors of the final outcome as judged by the trial physicians.

\section{Discussion}

These results need to be interpreted with caution because of the small numbers of patients in each treatment group and because of the relatively high withdrawal rate. Withdrawal of patients may affect $\stackrel{\vec{S}}{\rightarrow}$ the result of the trial in a number of ways. It could $\bar{C}$ be argued that patients receiving little benefit from the trial medication may be more likely to complain $\frac{\bar{m}}{\frac{7}{7}}$ of unwanted effects and hence be withdrawn. This $\stackrel{\varnothing}{\circledR}$ would bias the result in favour of patients who have responded well. We do not feel this factor played a $\vec{\bullet}$ significant part in this trial, as the majority of the dropouts occurred within the first 3 months before $\vec{\omega}$ the patient had been led to expect any noticeable $\stackrel{\sigma}{\circ}$ improvement. Withdrawals because of ineffectiveness could produce a similar bias; we had only 1 patient-in the $1.25 \mathrm{AZ}$ group-withdrawn for this reason.

A notable aspect of these results is the improve- $\circlearrowleft$ ment seen in the placebo group. The fact that this reached statistical significance for a number of variables is a reminder that the sheet anchor of $\geq$ testing the effectiveness of 'slow-acting' drugs in rheumatoid arthritis remains the double-blind com- $\stackrel{\oplus}{\oplus}$ parison with placebo, demanding though the $\vec{\theta}$ ethical and logistic aspects of this are.

These results confirm again that azathioprine in a daily dosage of $2.5 \mathrm{mg} / \mathrm{kg}$ is an effective slowacting drug in rheumatoid arthritis. The relatively small numbers in the treatment groups do not permit one to draw precise conclusions about the $\frac{\circ}{\mathbb{D}}$ effectiveness of $1.25 \mathrm{mg} / \mathrm{kg}$ daily compared with full doses and with placebo, but the general trend of the results leave no doubt that the half dosage group fell somewhere between the other 2 . It is tempting to interpret the lower dropout rate in the half-dosage group as pointing to a reduction in short-term effects compared with full dosage. In fact, this $\frac{0}{\circ}$ difference might well have occurred by chance.

We believe that azathioprine continues to have a $\delta$ place in the treatment of certain cases of severe rheumatoid arthritis. It is relatively easy to manage, 0 and short-term toxicity is troublesome rather than dangerous. ${ }^{1}$ It is the probable, slight risk of malignancy $^{3}$ which places it after penicillamine and gold in the choice of slow-acting drugs. Although the $\sigma$ mechanism of this oncogenesis is unknown and the $N$ relationship of risk to dosage unproved, it is never- N theless mainly this consideration which makes it obligatory to employ the minimum effective dosage. The message from this study is that, if one is to achieve the-admittedly modest-effect of azathio- $\stackrel{\infty}{\sim}$ prine in full, then it is probably necessary to start with a daily dose of about $2 \cdot 5 \mathrm{mg} / \mathrm{kg}$.

How long should full doses be continued? This study again shows that improvement in a slow- $\frac{\overrightarrow{\mathbb{D}}}{\mathbb{Q}}$ acting drug continues for at least 6 months. On this evidence it would seem reasonable to regard 6 
months on full doses as an adequate test of the effectiveness of the drug in an individual patient, while for those who both tolerate the drug and improve on it continuing full doses for a total of 1 year probably achieves maximum effectiveness. After 12 months there is a strong case for progressively reducing the dose to the minimum which will maintain this effect. Improvement may be maintained over a number of years on small daily doses, with the patient relapsing if the drug is finally withdrawn altogether. ${ }^{11}$ The striking parallel with the situation when azathioprine is used to prevent rejection of renal transplants ${ }^{12}$ perhaps points to the effectiveness of the drug depending on a similar mechanism in these 2 conditions.

\section{References}

1 Currey H L F, Harris J, Mason R M, et al. Comparison of azathioprine, cyclophosphamide, and gold in treatment of rheumatoid arthritis. Br Med J 1974; iii: 764-6.

2 Currey H L F. Immunosuppressive drugs in rheumatoid arthritis-toxicity. In: Fallet G H, Fischer T L. Selected Therapeutic Symposium, Geneva. Munich: Urban and Schwarzenberger, 1973: 98-104.
3 Kinlen L J, Sheil A G R, Peto J, Doll R. Collaborative United Kingdom-Australasian study of cancer in patients treated with immunosuppressive drugs. $\mathrm{Br} \mathrm{Med} \mathrm{J} \mathrm{1979;}$ ii: $1461-6$.

4 Mason M, Currey H L F, Barnes C G, Dunne J F, Hazelman B L, Strickland I D. Azathioprine in rheumatoid arthritis. Br Med J 1969; i: 420-2.

5 Goebel K M, Janzen R, Joseph K, Borngen U. Disparity between clinical and immune responses in a controlled trial of azathioprine in rheumatoid arthritis. Eur J Clin Pharmacol 1976; 9: 405-10.

6 Pinals R S. Azathioprine in the treatment of chronic polyarthritis: long-term results and adverse effects in 25 patients. Rheumatology 1976; 3: 140-4.

7 Cade R, Stein G, Pickering M, Schlein E, Spooner G. Low dose, long-term treatment of rheumatoid arthritis with azathioprine. Southern Med J 1976; 69: 388-92.

8 Dwosh I L, Stein H B, Urowitz M B, Smythe H A, Hunter T, Ogryzlo M A. Azathioprine in early rheumatoid arthritis. Arthritis Rheum 1977; 20: 685-91.

8 Taves D R. Minimisation: a new method of assigning to treatment and control groups. Clin Pharmacol Ther 1974; 15: 443-53.

10 Joyce C R B. Patient co-operation and the sensitivity of clinical trials. J Chron Dis 1962; 15: 1025-56.

11 De Silva M, Hazleman B L. Long-term azathioprine in rheumatoid arthritis-a double-blind study. Paper presented to the Heberden Society, London, 6 June 1980.

12 Hamburger J, Crosnier J, Dormont J, Bach J-F. Preparation and care of the patient. Azathioprine. Renal Transplantation, Theory and Practice. Baltimore: Williams and Wilkins, 1972: 151. 